\title{
List of abbreviations (additional to volumes 1-5)
}

DBH: Dresdner Beiträge zur Hethitologie.

Glocker, Ritual: Jürgen Glocker, Das Ritual für den Wettergott von Kuliwišna ("Eothen" 6, Firenze 1997).

Hagenbuchner, Massangaben: Albertine Hagenbuchner-Dresel, Massangaben bei hethitischen Backwaren (DBH Band 1 [2002]).

Kassian, HFR: Alexei Kassian, Andrej Korolëv, Andrej Sidel'tsev, Hittite Funerary Ritual šalliš waštaiš (AOAT Band 288, Münster 2002).

KuT: Kuşakli tablets.

Riemschneider, Omentexte: Kaspar Klaus Riemschneider, Die akkadischen und hethitischen Omentexte aus Boğazköy (DBH Band 12 [2004]).

Tischler, HHW: Johann Tischler, Hethitisches Handwörterbuch (IBS Band 102 [2001]).

Ünal, Ortaköy: Ahmet Ünal, Hittite and Hurrian Cuneiform Tablets from Ortaköy (Corum), Central Turkey (Istanbul, 1998). 
